\title{
Antropologia, etnografia e narrativa: caminhos que se cruzam na compreensão do processo saúde-doença*
}

\section{Anthropology, ethnography, and narrative: intersecting paths in understanding the processes of health and sickness}

\author{
Gabriela M.C. Costa \\ Docente do Departamento de Enfermagem/ \\ Universidade Estadual da Paraíba. \\ Programa de Pós-graduação Mestrado em Saúde Pública/UEPB \\ Rua Maria Eunice G. Fernandes, 154 \\ 58038480 - João Pessoa - PB - Brasil \\ gabymcc@bol.com.br \\ Dulce M.R. Gualda \\ Professora da Escola de Enfermagem/ \\ Universidade de São Paulo. \\ Departamento de Enfermagem Materno Infantil e Psiquiátrica/USP \\ Av. Dr. Enéas de Carvalho Aguiar, 419 \\ 05403000 - São Paulo - SP - Brasil \\ drgualda@usp.br
}

Recebido para publicação em maio de 2009. Aprovado para publicação em maio de 2010.
COSTA, Gabriela M.C.; GUALDA, Dulce M.R. Antropologia, etnografia e narrativa: caminhos que se cruzam na compreensão do processo saúdedoença. História, Ciências, Saúde Manguinhos, Rio de Janeiro, v.17, n.4, out.-dez. 2010, p.925-937.

Resumo

Discorre sobre antropologia, método etnográfico e narrativa como possibilidades de acessar os sentidos atribuídos e a experiência dos sujeitos. De uma perspectiva antropológica, o universo sociocultural é tomado como referência para a compreensão do significado do processo saúde-doença, através de uma descrição etnográfica densa, cuja análise tem inspiração interpretativista. Nesse contexto, as narrativas revelam-se como possibilidades para a compreensão do modo como as experiências humanas subjetivas são compartilhadas e de como são organizados os comportamentos, enfatizando-se o significado, o processo de produção de histórias, as relações entre o narrador e os demais sujeitos, os processos de conhecimento e a multiplicidade de formas para se captar experiências.

Palavras-chave: etnografia;

antropologia da saúde; narrativa.

Abstract

The article discusses anthropology, ethnographic method, and narrative as possible ways of coming to know subjects' experiences and the feelings they attribute to them. From an anthropological perspective, the sociocultural universe is taken as a point of reference in understanding the meaning of the processes of health and sickness, using a dense ethnographic description from an interpretivist analytical approach. In this context, narratives afford possible paths to understanding how subjective human experiences are shared and how behavior is organized, with a special focus on meaning, the process by which stories are produced, relations between narrator and other subjects, processes of knowledge, and the manifold ways in which experience can be captured.

Keywords: ethnography; anthropology of health; narrative. 
$\mathrm{E}$ ste artigo pretende, por meio de uma reflexão teórica, discorrer sobre a antropologia, o método etnográfico e a narrativa como possibilidades para acessar os sentidos atribuídos e a experiência dos sujeitos no que concerne ao processo saúde-doença, reconhecendo - assim como Raynaut (2006) - que o corpo representa a interface entre o natural e o social, e que fatos culturais estão na gênese da relação entre os fatores ambientais e os equilíbrios corporais.

As digressões teóricas relacionadas aos métodos e às técnicas de pesquisa precisam ser revistas e redirecionadas a uma abordagem que favoreça uma reflexão aprofundada, crítica e salutar, que nos conduza de uma percepção fragmentária do ser humano para uma concepção unitária. Nesse sentido, é necessário considerar as bases da história do pensamento e seus modos de interlocução com as ciências humanas e com os métodos de pesquisa qualitativa, a partir dos paradigmas positivista e fenomenológico.

\section{A abordagem antropológica}

$\mathrm{Na}$ abordagem de temas relacionados ao processo saúde-doença, considerar os diversos contextos sociais e culturais e lançar mão da antropologia pode representar, como afirma Gualda (1998), uma perspectiva complementar e enriquecedora. Essa abordagem permite uma nova construção de modelos de saúde-doença que recuperam a dimensão experiencial, bem como a psicossocial (Gualda, Bergamasco, 2004).

Para Chauí (1997), partindo de um resgate histórico, a antropologia é a ciência da humanidade e da cultura. Teria uma dimensão biológica, como antropologia física; uma dimensão filosófica, como antropologia filosófica; e uma dimensão sociocultural, como antropologia social e cultural. Para Helmam (2003), a principal diferença entre as duas últimas residiria no fato de a antropologia social conferir ênfase à forma de os grupos sociais se organizarem, ao passo que a antropologia cultural privilegiaria o modo como esses mesmos grupos veem o mundo que habitam. Constata-se, então, a diversidade dos campos de interesse e o fato de o homem e a cultura constituírem um foco comum, como uma dimensão na qual se articulam os conflitos e as concessões, as tradições e as mudanças, em que tudo ganha sentido (Minayo, 1999).

Especificamente na antropologia, a saúde não é vista somente como consequência de fatores sociais e econômicos, mas também, seguindo Caprara (2003, p.927), como "um produto culturalmente determinado". Nessa mesma perspectiva, Good (1994) afirma que a cultura é entendida como um conjunto de ideias, conceitos, regras e comportamentos compartilhados em um determinado grupo e que organiza a experiência da saúde e da doença nas distintas sociedades.

Lançando mão dessa vertente, estudiosos das mais diferentes áreas têm se preocupado em problematizar e, por conseguinte, compreender o processo saúde-doença através das experiências de colaboradores por todo o mundo (Mello, 1995). A compreensão do referido processo como fenômeno sociocultural evidencia que as experiências de saúde e doença são atravessadas pelos significados socialmente construídos, logo não podem ser desvinculadas das estruturas sociais mais abrangentes que permeiam as sociedades. 
Segundo Langdon (1996), a antropologia tem empreendido estudos para compreender a relação entre saúde e cultura desde 1924, com W.H.R. Rivers, que instituiu a medicina como categoria de pesquisa nas culturas não europeias e, em 1932, com Clements, que realizou um estudo comparativo sobre os conceitos de doença na medicina primitiva através das crenças etiológicas. Os trabalhos de Rivers, Clements e Erwin Ackerknecht - este último considerado fundador da antropologia médica nos EUA - fundamentam-se na ideia de que a medicina indígena representa um modo de pensamento qualitativamente distinto daquele da biomedicina, reconhecendo por conseguinte não haver uma medicina primitiva, mas sim uma pluralidade delas, cada uma ligada à sua cultura particular. Afirma-se, com isso, a diversidade cultural.

Ackerknecht (1985) reconhecia que a doença e seu tratamento somente são processos biológicos no sentido abstrato, e que os fatores sociais determinam a percepção do estado de doente, do diagnóstico da doença e do tratamento da mesma.

Em suas análises históricas, Langdon (1996) conclui que os primeiros antropólogos da saúde, Rivers e Ackerknecht, não pesquisaram questões ligadas aos interesses da biomedicina. Suas pesquisas foram particularmente importantes ao estabelecerem o estudo da etnomedicina como objeto de pesquisa antropológica. Para compreender o sistema de medicina de uma cultura, os pioneiros afirmaram ser necessário examiná-lo a partir de seu contexto sociocultural. No entanto, para esses autores, a cultura existiria a priori, sendo vista como um sistema fixo e homogêneo no qual todos os membros compartilham as mesmas ideias e agem de modo análogo.

$\mathrm{Na}$ tentativa de construir paradigmas nos quais o biológico estivesse articulado ao cultural, vários estudos foram empreendidos por antropólogos na década de 1960. Todavia, as novas discussões sobre a relação saúde/doença passaram a lidar, como afirma Langdon (1996), com um conceito dinâmico e heterogêneo de cultura, distinto daquele presente nos trabalhos de Ackerknecht, Rivers e Clements, reconhecendo-se, a partir de então, a doença como processo sociocultural e o conceito de doença como experiência.

Para Geertz (1989), a cultura deve ser compreendida como uma rede de significados que incluem conflitos e relações de poder presentes nas sociedades. Trata-se de uma construção simbólica do mundo sempre em transformação, no qual os atores sociais escrevem e reescrevem o texto cultural inseridos em determinado contexto, dentro do qual interpretam, organizam e dão sentido à sua existência. Langdon (1996) destaca que igualmente centrais nesse conceito da cultura é o enfoque do indivíduo como ser consciente que percebe e age, bem como o reconhecimento da doença como processo subjetivo, construído a partir de contextos socioculturais e vivenciado pelos atores.

Segundo Minayo (1998), a preocupação dos antropólogos com questões do processo saúde-doença passou, a partir dos anos 1960, a focalizar a compreensão dos sistemas de saúde, as relações estabelecidas entre profissionais e pacientes e os universos simbólicos relacionados aos fenômenos da vida, destacando a influência da antropologia interpretativa de Geertz nessa inflexão teórica. Clifford Geertz é provavelmente, depois de Claude LéviStrauss, o antropólogo cujas ideias causaram maior impacto na antropologia, na segunda metade do século XX - quer seja no campo teórico ou na prática. Ele é considerado fundador de uma das vertentes da antropologia contemporânea, a chamada antropologia 
hermenêutica ou interpretativa, que, como projeto de análise cultural, se propõe a compreender com base na interpretação dos significados que emergem da interação social, considerando a realidade concreta dos indivíduos (Eckert, 1994).

Ao tentar interpretar o texto, o antropólogo deve empenhar-se em compreender não somente o significado cultural, mas igualmente como falas, silêncios, gestos e ações ganham sentido para os atores sociais. Para Geertz (1989), o antropólogo lê o texto cultural por sobre os ombros dos nativos e elabora a interpretação a partir de uma descrição densa.

Considerando as reflexões de Cardoso de Oliveira (2000), o trabalho do antropólogo seria, em última instância, a construção do conhecimento partilhado através do olhar/ ouvir e escrever o fenômeno observável. Para ele, "o papel do antropólogo é descobrir a ordem cultural escondida nas relações sócias" (p.32). Sendo assim, o relato antropológico deve consistir na descrição densa de uma determinada interpretação da realidade, a do pesquisador - o que pode ser mais bem compreendido parafraseando o autor: "eu não descrevo a tribo, eu escrevo por meio dela".

Kleinman (1980), inspirado em Geertz, afirma que a cultura fornece modelos de e para interpretar comportamentos humanos. Por conseguinte, "o processo saúde-doença e todas as atividades de cuidados são respostas socialmente organizadas frente às doenças e podem ser estudadas como um sistema cultural ..." (Uchôa, Vidal, 1994, p.500). Em outras palavras, é a realidade simbólica que permitiria ao paciente atribuir significados a partir de sua experiência individual, segundo as normas sociais e culturais do seu grupo (Oliveira, 2002).

Com o desenvolvimento da corrente interpretativa em antropologia, surge uma nova concepção da relação entre indivíduo e cultura, tornando possível uma verdadeira integração da dimensão contextual na abordagem dos problemas de saúde (Uchôa, Vidal, 1994). Nesse sentido, para o antropólogo, a cultura é o contexto no qual os diferentes fenômenos se tornam inteligíveis. Tal concepção estabelece uma ligação entre as formas de pensar e agir dos indivíduos de um grupo e ressalta a importância da cultura na construção de todo evento humano. Nessa perspectiva, considera-se que percepções, interpretações e ações, até mesmo no campo da saúde, são culturalmente construídas.

A partir da antropologia geral - e influenciada pelo interpretativismo de Geertz desenvolveu-se a antropologia médica como ramo aplicado à epidemiologia e à clínica. Para Helman (2003), a antropologia médica analisa como as pessoas explicam as causas das doenças e seus tratamentos e, ainda, como elas são enfrentadas, considerando as diferenças entre os diversos grupos sociais. Estuda, igualmente, como tais crenças e práticas estão relacionadas a mudanças biológicas e psicológicas no organismo humano, tanto na saúde quanto na doença.

Para Cardoso de Oliveira (2000), não se trata de uma única antropologia, mas de várias orientações teóricas que ora bebem nas fontes de autores franceses (antropologia da doença), ora nas de norte-americanos (antropologia médica), ou ainda nas de autores nacionais (antropologia da saúde), sinalizando, por um lado, as múltiplas possibilidades de apreensão dos objetos etnográficos e, por outro, as peculiaridades da antropologia feita entre nós.

Em termos teóricos, podemos considerar que a antropologia médica difere da antropologia da saúde ao focar seus estudos nas racionalidades médicas, nas patologias e nos sistemas terapêuticos. Para Laplantine (1996), a antropologia da doença estuda a 
percepção das doenças e a resposta a elas de um determinado grupo social, elaborando e analisando modelos etiológicos e terapêuticos. De acordo com Becker e colaboradoras (2009), a antropologia da saúde considera que o ser humano precisa ser compreendido como um ser psicobiológico, ultrapassando-se a divisão cartesiana entre corpo e mente. Propõe, portanto, uma nova maneira de pensar e agir em relação ao corpo, à cultura e à individualidade de cada ser humano, apoiada na teoria da complexidade do pensador francês Edgar Morin. Nessa vertente, o ser humano forma uma unidade complexa na qual não é possível separar os fatores biológicos, psicológicos e culturais para descobrir sua essência. Parafraseando Geertz (1989, p.37), "sem os homens certamente não haveria cultura, mas, de forma semelhante, ... sem cultura não haveria homens".

A antropologia médica ressalta a existência de três dimensões na doença: disease, illness e sickness. Disease expressaria a realidade biológica da doença, do ponto de vista do profissional. Illness enfatizaria a experiência, a percepção individual e a reação social à doença. Sickness diria respeito à desordem em seu sentido genérico, que costuma ser usado pela população, relacionando-o às forças macrossociais culturais (Kleinman, 1988; Coelho, Almeida Filho, 2002). Para Kleinman (1980), todas as atividades de cuidados em saúde são respostas socialmente organizadas perante as doenças e podem ser estudadas como um sistema cultural. Todo sistema de cuidados em saúde seria, portanto, constituído pela interação entre três setores diferentes (profissional, tradicional e popular). A esses setores correspondem modelos explicativos dos profissionais e dos pacientes e suas famílias. Alguns autores sustentam que a interação de tais símbolos em uma rede semântica corresponde à construção de realidades médicas que conjugam normas, valores, expectativas individuais e coletivas, comportamentos ou formas específicas de pensar e agir em relação à doença e à saúde (Uchôa, Vidal,1994).

Os trabalhos desenvolvidos por Arthur Kleinman e Byron Good, dois dos principais representantes da corrente interpretativa em antropologia médica, fornecem os elementoschave de um quadro teórico e metodológico para a análise dos fatores culturais que intervêm no campo da saúde. Esses estudiosos, procurando enriquecer a análise de componentes não biológicos do fenômeno da saúde-doença, sistematizaram um modelo que atribui importância teórica aos aspectos social e cultural, negligenciados em aproximações sociológicas precedentes (Kleinman, Einsenberg, Good, 1978). Assim, Bosi (1988, p.112) afirma que todo evento é compreendido como um "acontecer vivido da existência que motiva as operações textuais", nelas penetrando como temporalidade e subjetividade, podendo transformar-se em objeto de estudo da antropologia médica.

Seguindo essa perspectiva, Uchôa e Vidal (1994) acreditam que a saúde de determinado sujeito (ou sociedade) é determinada por seu modo de vida, ou seja, pelos costumes, regras, normas, valores e crenças. Sendo assim, os autores apontam alterações nestes últimos como condição sine qua non para reverter a experiência da doença em saúde.

Da perspectiva interpretativa contemporânea, o modelo de saúde aporta uma crítica ao pressuposto da universalidade dos padrões saúde-doença e afirma sua determinação cultural por meio de um sistema de cuidados com a saúde. Este último seria composto por três setores: o da cura profissional, o das curas populares e aquele de crenças, escolhas, decisões, papéis, relacionamentos, interações e instituições (Kleinman, 1988). 
A diferença entre conhecimentos médicos e práticas populares é objeto de discussão e estudo no interpretativismo. Os conhecimentos são adquiridos por meio do estudo, ao passo que sua aplicabilidade somente pode ser alcançada por intermédio de um longo processo experiencial (Gadamer, 1994). Nesse sentido, Coelho e Almeida Filho (2002, p.321) consideram que "a experiência da doença e os padrões de saúde variam em diferentes sociedades, tendo como fator determinante a posição socioeconômica e a subcultura de quem os concebe".

Para Caprara (2003, p. 929), é provável que, pelo fato de a "medicina ocidental ser considerada como área pertencente às ciências naturais, os seres humanos sejam, frequentemente, muito analisados do ponto de vista biológico". Todavia, a perspectiva interpretativa vê os indivíduos como capazes de superar os limites biológicos do corpo e as explicações biomédicas do homem, considerando-os sujeitos que refletem e vivenciam a experiência subjetiva no processo saúde-doença, tendo-se em conta a organização social e econômica em que estão inseridos. De acordo com Helmam (2003, p.15), os antropólogos afirmam que "em todas as sociedades humanas, as crenças e as práticas relacionadas aos problemas de saúde são um elemento central da cultura". Assim, do mesmo modo como é preciso conhecer a cultura dos indivíduos para notar se reagem de forma semelhante ou diferente diante da doença, da morte, de infortúnios e outros, também é preciso conhecer sua cultura para ver a que se atribui as causas de uma determinada doença e como se concebe seu tratamento (Uchôa, Vidal, 1994).

Kleinman, Eisenberg e Good (1978) e Kleinman (1980) afirmam literalmente que a experiência da doença é moldada culturalmente, o que determina a maneira como a percebemos e buscamos superá-la. Ancorados nesses autores, podemos dizer que aprendemos a ficar doentes de acordo com o nosso meio social, que influencia diretamente a forma como sentimos as doenças, expressamos seus sintomas e utilizamos os recursos de cura à nossa disposição.

Segundo a literatura pertinente, ao interpretar a teia de significados o fazer antropológico estaria elaborando uma descrição etnográfica. De acordo com Shirley (1987), a publicação do estudo de Malinowski, Os argonautas do Pacífico ocidental, em 1922, marcou a história da antropologia moderna ao propor uma nova forma de etnografia, envolvendo detalhada e atenta observação participante de aspectos da vida dos melanésios, tais como práticas econômicas, relações familiares, religião, mito e poesia. Seu objetivo consistiu em analisar intensiva e continuadamente a microssociedade, sem se referir à sua história, uma vez que acreditava ser mais interessante analisar como a sociedade se apresentava no momento presente do que indagar de que modo ela chegou a ser o que era (Malinowski,1984).

\section{O método etnográfico}

De acordo com Vidich e Lyman (2000), as primeiras observações etnográficas consistiram em relatos e descrições oferecidos da perspectiva do conquistador e civilizador de povos, pelos administradores das colônias, missionários e bucaneiros. Na tentativa de elaborar uma linha do tempo, os autores afirmam que as descrições etnográficas se reconfiguram e 
deixam de abordar o universo cristão, passando a empreender esforços no sentido de compreender o desenvolvimento das sociedades e culturas ao estudar as teorias da evolução social por meio da aplicação dos princípios evolucionistas de Darwin. Após a proposição do método comparativo, feita por Auguste Comte, a investigação etnográfica passou a classificar as culturas a partir do referencial europeu, reconhecendo etapas de transição progressiva e irreversível que iriam da selvageria, passando pelo barbarismo, até chegar à civilização.

Nesse contexto, passou-se a discutir a importância de a coleta de dados ser realizada pelo pesquisador. Assim, segundo descrição de Vidich e Lyman (2000), em 1874, a Associação Britânica Pelo Avanço da Ciência publicou o caderno Notes and queries on anthropology (Notas e questões sobre antropologia), com a intenção de orientar a tarefa dos etnógrafos em sua inserção no campo. De posse dessas recomendações, Bronislaw Malinowski viajou para o Pacífico com o intuito de estudar os trobriandeses, em 1914. Naquele ano, algumas hostilidades da Primeira Guerra ocorreram nas colônias e territórios das nações europeias, no continente africano e no Oceano Pacífico, o que alterou as rotas de navegação. Devido a essas alterações, o pesquisador permaneceu na localidade até 1918, o que viabilizou o desenvolvimento de estudos com base em uma convivência prolongada. Assim, inaugurou a observação participante e transformou a antropologia em uma ciência da alteridade. Juntamente com Franz Boas, Malinowski explorou a distância que separava sua sociedade daquela por ele investigada. As obras de ambos, respectivamente $A$ alma primitiva e $O s$ argonautas do Pacífico ocidental, são exemplos do exercício de alteridade na elaboração da experiência etnográfica, tão necessária à formação de um antropólogo, ainda nos dias de hoje.

Na introdução de sua obra clássica, Malinowski (1984) sistematiza o método etnográfico como método de pesquisa de campo. Descreve minuciosamente as etapas de aproximação com os nativos e de uma profunda imersão no campo, imersão esta que deve possibilitar a expressão das práticas culturais observadas. Em seguida, o autor recomenda que se passe ao distanciamento, para que o pesquisador possa realizar a tarefa de reconstrução da experiência observada diretamente no convívio, ou seja, a etapa de descrição etnográfica. Malinowski também menciona como necessários o domínio da língua nativa e o conhecimento das teorias existentes sobre a vida na sociedade em questão. Tais princípios, elementares do fazer antropológico no estudo de outra sociedade, acabaram por se tornar princípios básicos de qualquer pesquisa de campo, a base necessária para qualquer etnografia. Assim, esta última constitui o núcleo do fazer antropológico, do (re)elaborar interpretações com o intuito de demonstrar a diversidade moral e cultural da humanidade.

Segundo Geertz (1989), o que torna um texto etnográfico plausível e convincente é a capacidade do autor de demonstrar ter penetrado - e ter sido penetrado - pelo outro. Nesse sentido, a obra etnográfica nunca é a verdade sobre o outro, mas invariavelmente uma interpretação do autor. Ou seja, é resultado de seu trabalho de campo e não a realidade propriamente dita; um discurso nem falso nem verdadeiro, representando apenas uma das dimensões de uma realidade multifacetada (Fonseca, 1999).

A etnografia constrói-se baseada na ideia de que os comportamentos humanos só podem ser devidamente compreendidos e explicados se tomarmos como referência o contexto 
social no qual são observados (Victora, Kanuth, Hassen, 2000). Para Gualda (2002), tratase de um dos métodos qualitativos mais antigos nas ciências sociais, essencial para a antropologia cultural. O fazer etnográfico pressupõe uma 'descrição densa' da interpretação própria que cada indivíduo faz das coisas, dos acontecimentos, dos fatos, dos fenômenos; todos esses elementos estando assentados no pano de fundo cultural (Geertz, 1989). Já há algum tempo é utilizado entre antropólogos e sociólogos em suas pesquisas e igualmente em outras áreas, como a enfermagem, por exemplo.

O método etnográfico define-se pelas técnicas de entrevista e observação participante para coleta de informações, mas elas não são as únicas. A familiaridade com a bagagem acumulada pela antropologia e o estudo do universo empírico possibilitam ao pesquisador optar pelas técnicas mais adequadas ou compatíveis às situações observadas. Circunstancialmente, o convívio com a realidade social revela-se a única forma de penetrar no modo de vida de um grupo e sintonizar-se com os planos comunicativos em que se movem (Cardoso de Oliveira, 2000). Mais recentemente, o estudo sobre as narrativas vem sendo explorado como método capaz de favorecer a análise, na perspectiva antropológica de entender palavras e expressões dos atores sociais, o sentido do ser doente ou saudável, reconstruindo-se a lógica das representações produzidas e socializadas durante a sua construção e contribuindo, desse modo, para a compreensão de sua visão de mundo.

$\mathrm{Na}$ área da saúde, a etnografia foi incorporada por enfermeiras antropólogas, tendo como ponto de partida a investigação de condutas socialmente modeladase, como propósito, compreender o fenômeno saúde-doença a partir do ponto de vista e do contexto dos informantes (Morse, Field, 1996; Costa, 2004). Por essa razão, tal opção envolve, como observam Gualda, Merighi e Oliveira (1995), a atitude de aprender com eles, ou seja, "compreender como as crenças, os valores e as práticas populares interferem no processo saúde-doença" (p.299).

De acordo com Hammersley (1998), o naturalismo, a compreensão e a descoberta são princípios norteadores dos estudos etnográficos, referindo-se, respectivamente, ao fato de apreender os fatos e/ou comportamentos humanos nos contextos em que ocorrem, à necessidade de se considerar a perspectiva cultural ao se empreender uma interpretação de estímulos e a construção de respostas e, por último, à característica de tratar-se de um processo indutivo ou baseado na descoberta, ao contrário dos que testam hipóteses.

Empreender uma pesquisa etnográfica implica, por um lado, aguçar a sensibilidade, uma atenção meticulosa a tudo que diz respeito à vida dos colaboradores da pesquisa e, por outro, o desvendamento correlato dos contextos em relações aos quais se situam as perspectivas e o conjunto de valores do próprio pesquisador (Costa, 2004). Esse tipo de pesquisa impõe, como grandes desafios, o confronto contínuo do pesquisador com seu horizonte teórico e o exercício permanente de sua autorreflexão e crítica. O pesquisador pode, não raras vezes, encontrar dificuldade para incorporar as vozes e as reais motivações dos parceiros - os colaboradores - ao diálogo que se inicia com a pesquisa.

Por fim, há de se considerar, como sugere Minayo (1998), a etnografia como método por intermédio do qual se busca descrever a questão da saúde, da doença e/ou do cuidado dentro de um universo amplo e complexo de relações sociais, políticas, econômicas, 
domésticas e cosmológicas, em que as compreensões de saúde e doença dos sistemas médicos e das práticas de saúde integram o quadro geral da ordem social.

\section{A narrativa}

A partir do exposto, entende-se que a antropologia considera a saúde e tudo a ela relacionado como fenômenos culturalmente construídos e interpretados. Os estudos dessa disciplina buscam, assim, revelar a complexidade da experiência do processo saúde-doença e, para tanto, lançam mão da etnografia para descrever esse processo, que adquire relevância na voz, sob a forma narrativa, daqueles que compartilham a experiência de vivenciar, explicar e interpretar os fenômenos. Nessa perspectiva, a narrativa é percebida como um evento social e não como texto fixo.

Durante um bom tempo, os antropólogos mantiveram-se fiéis a um formato razoavelmente uniforme e aparentemente natural - carregado de certo tabu estilístico - e não pensaram muito em termos de narrativa (Price, 2004). A publicação do trabalho Writing culture (A escrita da cultura; Clifford, Marcus, 1986) marcou uma mudança radical na escrita etnográfica, ao sustentar que a antropologia possui não somente uma política, mas também uma poética no redigir. De acordo com Rosaldo (1989), dali por diante ficou evidente que distintas situações históricas e culturais podem ser escritas de formas literárias diversas, cabendo ao etnógrafo a busca por uma forma retórica - de visão e escrita - mais ampla do que a utilizada no período clássico.

O uso da narrativa na medicina e na prática terapêutica data do fim do século XIX, nos escritos de Freud (Mattingly, Garro, 2000). Narrar as experiências do processo psicoterapêutico fornece a oportunidade para paciente e terapeuta desenvolverem versões alternativas das histórias e criarem compreensões novas quando revisitam, do passado, uma opinião própria ou de outrem, bem como novos trajetos para o futuro. A narrativa, para Good (1994), passou a constituir uma modalidade alternativa da representação que, de algum modo, é mais apropriada a determinados aspectos da experiência clínica.

De acordo com Becker e colaboradoras (2009), ao ouvir as narrativas dos sujeitos sobre suas experiências, é possível compreender a perspectiva subjetiva da doença sob uma vertente fenomenológica. Para as autoras, devemos considerar a narrativa como o caminho mais coerente para a descoberta das realidades culturais sobre saúde e doença. Todavia, elas chamam a atenção para a qualidade dos diálogos e para a compreensão das comunicações.

A narrativa, como habilidade humana, revela a relação entre o indivíduo e a cultura, contribuindo para o desenvolvimento ou a manutenção de atitudes e valores em contextos específicos e, por conseguinte, de significados. As narrativas não são simplesmente relatos da experiência; elas favorecem a experiência compartilhada e a organização do comportamento, reportando-se ao tempo e ao espaço essenciais à compreensão das experiências e sempre enfatizando a relação entre os sujeitos e a pluralidade dos acontecimentos. Outro aspecto evidenciado pela análise das narrativas diz respeito às relações sociais como suporte de referências para a compreensão dos fenômenos relacionados à saúde e à doença, com o objetivo de superar a distinção entre sujeito e objeto na pesquisa científica (Good, Good, 1982; Rabelo, Alves, 1999; Geanellos, 2000). Para Canesqui (2003, p.111), a "experiência 
não decorre apenas de modelos internalizados, sendo o indivíduo um personagem capaz de comunicar e refletir sobre ela".

Os estudos de caso ou as histórias de vida consideram a enfermidade a partir da interpretação do senso comum sobre a experiência vivida dos adoecidos e de seus familiares, diferentemente da abordagem médica, que concebe a doença como fenômeno eminentemente patológico e biológico. Desse modo é possível, para o pesquisador, reconstruir as interpretações, ambiguidades e incertezas das narrativas e práticas diante das doenças, bem como as opções de tratamento e suas avaliações (Alves, 1993, 1994; Canesqui, 2003).

Para Ricouer (1984), a narrativa pode ser definida como uma metáfora. Como tal, "fornece uma lógica para explicar os eventos, para compreender a experiência da saúde e doença, contemplando o abstrato pelo caminho do concreto" (Mattingly, Garro, 2000, p.22; tradução livre). Ela seria, assim, a forma fundamental para se entender a vida em seu fluxo temporal, evocar imagens sensoriais e entrelaçar cenas e símbolos mesmo quando contraditórios. Oferece, assim, explanações contraditórias da mesma história; afinal, as pessoas, ao (re)construírem suas narrativas, o fazem a partir de um contexto cultural amplo e de modelos compartilhados.

Em retórica, a metáfora é uma figura de linguagem, uma forma estilística que modifica o sentido de uma palavra substituindo-a por outra. Todavia não deve ser compreendida como simples adorno; ela se revela, na disciplina antropológica, como um recurso nos processos de expressão, interpretação e comunicação do significado das experiências. Poderse-ia dizer, conforme sugerem Rabelo e Alves (1999, p.180), que "o efeito das metáforas consiste em transportar através da objetividade da linguagem o outro (intelectual, sensível e emotivamente) para o drama apresentado".

De fato, parece inexistir outro caminho para descrever o tempo vivido, salvo sob a forma narrativa. A narrativa imita a vida, a vida imita a narrativa (Bruner, 2004). Esta última não se limita à reconstrução do passado, sendo usada para expressar a compreensão de um momento atual da vida e, igualmente, para antecipar o futuro (Mattingly, Garro, 2000). Além disso, fornece as contradições entre uma experiência individual e as expectativas baseadas em modelos culturais compartilhados. Para Mattingly e Garro, as narrativas sobre enfermidades não são ficções culturais, tampouco podem ser reduzidas a simples relatos da experiência. Em sua essência, descrevem experiências compartilhadas e organizam comportamentos; são, portanto, sociais e intersubjetivas e seu contexto deve ser submetido a cuidadosa observação.

Há muitas maneiras de contar histórias e muitas lentes através das quais elas podem ser interpretadas. A perspectiva da narrativa revela-se uma maneira de descrever, analisar e interpretar as histórias. Para tanto, Mattingly e Garro (2000) sugerem ser necessário que os episódios estejam selecionados entre a vasta escala das possibilidades no fluxo da experiência, e apresentados em uma ordem própria que revele intencionalmente ou não os significados. Além do mais, o aspecto social adquirido pela voz na narrativa, na descrição dos eventos, tem um interesse particular em pesquisas etnográficas. Características como entonação e qualidade da voz devem ser consideradas, além da apreciação da linguagem não verbal, tais como gestos e expressões. 
Uma narrativa completa envolve, por definição, um evento ou uma série deles (que aconteceram ou que se supõe terem acontecido no passado), a experiência (imagens, reações, sentimentos e significados atribuídos aos eventos relatados) e a narrativa, isto é, a forma linguística, visual ou musical de relatar o significativo (Cortazzi, 2001).

De acordo com Lieblich e Josselson (1998), a narrativa pode ser compreendida como uma modalidade interpretativa da pesquisa em que, a partir de uma pergunta, a entrevista flui sobre uma realidade interna, subjetiva da pessoa, em particular sobre o significado que ela atribui a algum fato de sua experiência. Assim, ela não relata simplesmente eventos, mas também coloca em evidência seu significado, relevância e importância. A análise estrutural pode ser empreendida ao se dividir as partes de uma narrativa em, pelo menos, três categorias principais: a estrutura do evento, que relata os acontecimentos; a estrutura da descrição, que fornece informações como tempo, lugar, pessoas e contexto, necessárias para a compreensão da narrativa; e a estrutura da avaliação, que revela a visão, a perspectiva e/ou o julgamento de quem está falando - considerada a parte mais importante (Cortazzi, 2001).

Algumas razões podem ser sugeridas para proceder a uma análise narrativa como parte da etnografia. As principais referem-se ao interesse pelo significado da experiência, da voz, das qualidades humanas em dimensões pessoais ou profissionais e de pesquisa como uma história (Cortazzi, 2001). A análise narrativa não pretende categorizar e classificar o mundo e sim interpretar, mostrar o significado e criar explanações para a experiência.

\section{Considerações finais}

Pode-se concluir que a abordagem antropológica, a etnografia e o uso das narrativas permitem apreender o modo de viver dos sujeitos em seu ambiente e favorecem a compreensão dos eventos relacionados ao processo saúde-doença. Estudos revelam que os comportamentos de uma população perante seus problemas de saúde, incluindo a utilização dos serviços médicos disponíveis, são construídos e partilhados a partir de universos socioculturais específicos.

É fato que as sociedades têm significados e coerência próprios, com sistemas perfeitamente elaborados. Assim é que, para a antropologia, cada cultura atende às necessidades do indivíduo criando instituições (econômicas, jurídicas, políticas, educativas) que deem respostas coletivas e organizadas, resultando em soluções que articulam o social, o biológico e o psicológico. Nesse contexto, a etnografia, envolvendo detalhada e atenta observação participante dos aspectos da vida, interessa-se não em saber como a sociedade chegou a ser o que é, mas sim em saber o que ela é no presente.

Em uma perspectiva etnográfica, as narrativas, como técnica situada entre as metodologias qualitativas, não são simplesmente respostas. Não são pacotes prontos esperando para serem expressos em respostas incentivadas por perguntas, em uma determinada entrevista. Uma narrativa é frequentemente precedida por uma proposta para se contar uma história e a aceitação em ouvi-la. Narrar eventos é uma atividade relacional empática que envolve, de um lado, alguém que, ao falar, consulta a história inteira da vida, um amálgama de materiais autobiográficos; e, de outro, um ouvinte com escuta atenta. Todavia podem existir lacunas entre a experiência - a narrativa -, a análise e a leitura final, uma vez que a narrativa pode ser afetada pelos processos da memória. 


\section{NOTA}

* Este artigo baseia-se na tese Deixar de ser mulher: conhecimento e significado da menopausa, de Gabriela M.C. Costa, apresentada ao Programa Interunidades de Doutoramento em Enfermagem, da Universidade de São Paulo, em 2007.

\section{REFERÊNCIAS}

ACKERKNECHT, Edwin.

Medicina e antropologia. España: Akal.

1985.

ALVES, Paulo César.

O discurso sobre a enfermidade mental. In:

Alves, Paulo César; Minayo, Maria Cecília de S.

(Org.). Saúde e doença: um olhar antropológico.

Rio de Janeiro: Fiocruz. p.91-99. 1994.

ALVES, Paulo César.

A experiência da enfermidade: considerações teóricas. Cadernos de Saúde Pública, Rio de Janeiro, v.9, n.3, p.263- 271. 1993.

BECKER, Sandra Greice et al.

Dialogando sobre o processo saúde/doença com a antropologia: entrevista com Esther Jean Langdon. Revista Brasileira de Enfermagem, São Paulo, v. 62, p.323-326. 2009.

BOSI, Alfredo.

Céu, inferno: ensaios de crítica literária e ideológica. São Paulo: Ática. 1988.

BRUNER, Jerome.

Life as narrative. Social Research, New York, v.71, n.3, p.691-710. 2004.

CANESQUI, Ana Maria.

Os estudos de antropologia da saúde/ doença no Brasil na década de 1990. Ciência \& Saúde Coletiva, Rio de Janeiro, v.8, n.1, p.109-124. 2003.

CAPRARA, Andrea.

Uma abordagem hermenêutica da relação saúde-doença. Cadernos de Saúde Pública, Rio de Janeiro, v.19, n.4, p.923-931. 2003.

CARDOSO DE OLIVEIRA, Roberto. O trabalho do antropólogo. Brasília: Paralelo 15. 2000.

CHAUÍ, Marilena.

Convite à filosofia. São Paulo: Ática. 1997.

CLIFFORD, James; MARCUS, George.

Writing culture: the poetics and politics of ethnography. Berkeley: University of California Press. 1986.

COELHO, Maria Thereza Ávila Dantas;

ALMEIDA FILHO, Naomar.

Conceitos de saúde em discursos

contemporâneos de referência científica.

História, Ciências, Saúde - Manguinhos, Rio de

Janeiro, v.9, n.2, p.315-333. 2002.
CORTAZZI, Martin.

Narrative analysis in ethnography. In:

Atkinson, Paul et al. Handbook of ethnography. London: Sage Publications. p.63-86. 2001.

COSTA, Maria Cristina Silva.

Afinação dos instrumentos: delineamento da pesquisa etnográfica In: Conferência

Internacional do Brasil de Pesquisa Qualitativa,

1, 2004, Taubaté. Anais... Taubaté: Unitau.

CD-Rom. 2004.

ECKERT, Cornelia.

A antropologia na atualidade. Revista Anos 90, São Paulo, v.10, n.2, p.7-35. 1994.

FONSECA, Claúdia.

Quando cada caso NÃO é um caso: pesquisa etnográfica e educação. Revista Brasileira de Educação, São Paulo, n.10, p.1-35. 1999.

GADAMER, Hans George.

Verdade e método: traços fundamentais de uma hermenêutica filosófica. Petrópolis: Vozes. 1994.

GEANELLOS, Rene.

Exploring Ricoeur's hermeneutic theory of interpretation as a method of analysing research texts. Nursing Inquiry, Carlton, v.7, p.112-119. 2000.

GEERTZ, Clifford.

A intepretação das culturas. Rio de Janeiro: Guanabara Koogan. 1989.

GOOD, Byron.

Medicine, rationality, and experience: an anthropological perspective. Nova York: Cambridge University Press. 1994.

GOOD, Byron; GOOD, Mary-Jo Delvecchio. Toward a meaning centered analysis of popular illness categories: 'fright illness' and 'heart distress' in Iran. In: Marsella, Anthony; White, Geoffrey Miles (Ed.). Cultural conceptions of mental health and therapy. Dordrecht: Reidel. p.149-164. 1982.

GUALDA, Dulce Maria Rosa.

Eu conheço minha natureza: a expressão cultural do parto. Curitiba: Maio. 2002.

GUALDA, Dulce Maria Rosa.

A experiência, o significado e a realidade da enfermeira obstetra: um estudo de caso. Tese (Livre-docência) - Escola de Enfermagem, Universidade de São Paulo, São Paulo, 1998. 
GUALDA, Dulce Maria Rosa; BERGAMASCO, Roselena Bazilli.

Processo saúde-doença: evolução de um conceito. In: Gualda, Dulce Maria Rosa; Bergamasco, Roselena Bazilli (Org.).

Enfermagem, cultura e o processo saúde-doença. São Paulo: Ícone. p.37-45. 2004.

GUALDA, Dulce Maria Rosa; MERIGHI, Miriam Aparecida Barbosa; OLIVEIRA, Sonia Maria Junqueira Vasconcelos de.

Abordagens qualitativas: sua contribuição para a enfermagem. Revista da Escola de Enfermagem da USP, São Paulo, v.29, n.3, p.297-309. 1995.

HAMMERSLEY, Martyn.

Reading etnography research: a critical guide. London: Longman. 1998.

HELMAN, Cecil G.

Cultura, saúde e doença. Porto Alegre: Artmed. 2003.

KLEINMAN, Arthur.

The illness narratives: suffering, healing \& the human condition. New York: Basic Books. 1988.

KLEINMAN, Arthur.

Patients and healers in the context of cultures: an exploration of boderland between anthropology and psychiatry. Berkeley: University of California Press. 1980.

KLEINMAN, Arthur; EINSENBERG, Leon; GOOD, Byron.

Culture, illness, and care: clinical lessons from anthropologic and cross-cultural research. Annals of Internal Medicine, Philadelphia, v.88, p.251-258. 1978.

LANGDON, Esther Jean.

A doença como experiência: a construção da doença e seu desafio para a prática médica. Florianópolis: UFSC. 1996.

LAPLANTINE, François. Aprender antropologia. São Paulo: Brasiliense. 1996.

LIEBLICH, Amia; JOSSELSON, Ruthellen A. The narrative study of lives. London: Sage Publications. 1998

MALINOWSKI, Bronislaw.

Introdução: tema, método e objetivo desta pesquisa. In: Malinowski, Bronislaw. Argonautas do Pacífico ocidental: um relato do empreendimento e da aventura dos nativos nos arquipélagos da Nova Guiné. São Paulo: Abril Cultural. p.4-9. 1984.

MATTINGLY, Cheryl; GARRO, Linda C. Narrative and the cultural construction of illness and healing. London: University of California Press. 2000.
MELLO, Luiz Gonzaga.

Antropologia cultural: iniciação, teoria e temas. Petrópolis: Vozes. 1995.

MINAYO, Maria Cecília.

$O$ desafio do conhecimento: pesquisa qualitativa em saúde. São Paulo: Hucitec. 1999.

MINAYO, Maria Cecília.

Introdução à metodologia de pesquisa social.

São Paulo: Hucitec. 1998.

MORSE, Janice M.; FIELD, Peggy Anne. Nursing research: the application of qualitative approaches. London: Stanley Thornes. 1996.

OLIVEIRA, Francisco Arsego.

Anthropology in healthcare services: integrality, culture and communication. Interface: Comunicação, Saúde, Educação, Botucatu, v.6, n.10, p.63-74. 2002.

PRICE, Richard.

Meditação em torno dos usos da narrativa na antropologia contemporânea. Horizonte Antropológico, São Paulo, v.10, n.21, p.293-312. 2004.

RABELO, Miriam Cristina; ALVES, Paulo César. Significação e metáforas na experiência da enfermidade. In: Rabelo, Miriam Cristina M.; Alves, Paulo César B.; Souza, Iara Maria A. (Ed.). Experiência de doença e narrativa. Rio de Janeiro: Editora Fiocruz. p.37-52. 1999.

RAYNAUT, Claude.

Interfaces entre a antropologia e a saúde: em busca de novas abordagens conceituais. Revista Gaúcha de Enfermagem, Porto Alegre, v.27, n.2, p.149-65. 2006.

RICOUER, Paul.

Time and narrative. Chicago: University of Chicago Press. 1984.

ROSALDO, Renato. Culture and truth: the remaking of social analysis. Boston: Beacon Press. 1989.

SHIRLEY, Robert Weaver. Antropologia jurídica. São Paulo: Saraiva. 1987.

UCHÔA, Elizabeth; VIDAL, Jean Michel. Antropologia médica: elementos conceituais e metodológicos para uma abordagem da saúde e da doença. Cadernos de Saúde Pública, Rio de Janeiro, v.10, n.4, p.497-504. 1994.

VICTORA, Ceres Gomes; KNAUTH, Daniela Riva; HASSEN, Maria de Nazareth Agra. Pesquisa qualitativa em saúde: uma introdução ao tema. Porto Alegre: Tomo Editorial. 2000.

VIDICH, Arthur J.; LYMAN, Stanford M. Qualitative methods: their history in sociology and anthropology. Newburry Park: Sage. 2000. 